\title{
LIFE CYCLE COST PADA GEDUNG BOARDING HOUSE DAERAH GLAGAHSARI, YOGYAKARTA
}

\author{
Ia Nadira PUHESSTI \\ ${ }^{1}$ Jurusan Teknik Sipil, Fakultas Teknik, Universitas Atma Jaya Yogyakarta, Yogyakarta, Indonesia \\ Email korespondensi: ianadira.p01@gmail.com
}

[diterima: 28 Maret 2021, disetujui: 10 Juni 2021]

\begin{abstract}
The number of students' interest in studying in the city of Yogyakarta is directly proportional to the demand for housing. To meet the demand for habitable residential buildings, the owner must think about the life time of the building and take care of the building, this has an impact on the costs incurred by the owner. By conducting a Life Cycle Cost analysis, a solution can be found so that the costs incurred by the owner are more economical. Life Cycle Cost is a tool to control costs with a basic estimate from the beginning of building planning and maintenance after construction is also calculated according to the life time of the building. To be able to calculate the Life Cycle Cost, components are consisting of initial costs, maintenance costs, operational costs, replacement costs and changes in function, and salvage value. With these components, the costs to be incurred for each component or building element can be seen. Life Cycle Cost analysis is calculated over a period of 25 years. The study was conducted at a boarding house in Glagahsari, Yogyakarta. The estimation of the overall cost of the building using the Life Cycle Cost method carried out at the boarding house located in Glagahsari is divided into three groups of estimated costs, namely the initial cost of IDR $1,261,887,141$ with a percentage of $54.97 \%$, maintenance cost of IDR $427,879,959$ with a percentage of $18,64 \%$, and operational costs of Rp. 605,914,200 with a percentage of $26.39 \%$.
\end{abstract}

Key words: Life Cycle Cost, cost, life time building.

\section{INTISARI}

Banyaknya minat pelajar untuk menuntut ilmu di Kota Yogyakarta berbanding lurus dengan permintaan tempat tinggal. Untuk memenuhi permintaan bangunan tempat tinggal yang layak huni, owner harus memikirkan tentang usia bangunan dan melakukan perawatan terhadap bangunan. Hal ini berdampak pada biaya yang akan dikeluarkan oleh owner. Dengan melakukan analisis Life Cycle Cost, dapat dicari solusi agar biaya yang akan dikeluarkan oleh owner lebih ekonomis. Life Cycle Cost merupakan alat untuk mengontrol biaya dengan estimasi dasar dari awal perencanaan gedung dan pemeliharaan pasca pembangunan juga dihitung sesuai usia gedung. Untuk dapat menghitung Life Cycle Cost, terdapat komponen yang terdiri dari biaya awal, biaya perawatan, biaya operasional, biaya penggantian dan perubahan fungsi, dan salvage value. Dengan adanya komponen tersebut, dapat diketahui biaya yang akan dikeluarkan untuk tiap komponen atau elemen bangunan. Life Cycle Cost Analysis dihitung dengan jangka waktu 25 tahun. Studi dilakukan pada bangunan boarding house yang berada di Glagahsari, Yogyakarta. Estimasi biaya keseluruhan gedung dengan metode Life Cycle Cost yang dilakukan pada bangunan boarding house yang berlokasi di Glagahsari terbagi menjadi tiga kelompok estimasi biaya yaitu initial cost sebesar Rp.1.261.887.141 dengan persentase 54,97\%, maintanance cost sebesar Rp.427.879.959 dengan persentase 18,64\%, dan operational cost sebesar Rp.605.914.200 dengan persentase $26,39 \%$.

Kata kunci: Life Cycle Cost, biaya, usia gedung.

\section{PENDAHULUAN}

Tiap tahun Yogyakarta mengalami kenaikkan jumlah populasi pelajar yang akan melanjutkan pendidikan. Hal ini berbanding lurus dengan jumlah kebutuhan tempat tinggal di Yogyakarta. Untuk memenuhi permintaan 
tempat tinggal di Yogyakarta, maka banyak dibangun bangunan tempat tinggal berupa boarding house atau asrama yang ditujukan untuk pelajar. Bangunan diharapkan memiliki usia pakai yang panjang, maka dibutuhkan perawatan agar fungsi dari bangunan tetap berjalan dengan baik. Penting untuk mempertimbangkan desain yang efisien selama bangunan beroperasi dan tentunya ekonomis. Bahan bangunan yang digunakan juga harus tepat agar tidak cepat mengalami kerusakan yang mengakibatkan pemeliharaan yang lebih rutin. Semakin rutin melakukan pemeliharaan, maka tingkat penggantian dan perbaikan akan sering dilakukan selama umur rencana bangunan. Hal ini akan mengakibatkan pembengkakan biaya pemeliharaan dan akan mempengaruhi biaya keseluruhan bangunan.

Untuk mempertimbangkan desain yang efisien dan ekonomis selama umur pakai bangunan, dapat digunakan metode Life Cycle Cost (LCC). Biaya siklus hidup atau ( $L C C)$ merupakan alat untuk mengontrol biaya dengan perkiraan pada awal perencanaan gedung yang akan dipakai untuk pemeliharaan sesuai umur gedung. Untuk menghitung Life Cycle Cost (LCC) perlu memahami bagian dari keseluruhan gedung yang akan dibangun. Hal ini agar dapat mengetahui biaya yang akan dikeluarkan untuk tiap komponen atau elemen bangunan.

Tujuan yang ingin dicapai pada studi adalah mengetahui apa itu $L C C$ atau biaya siklus hidup dan untuk menghitung biaya bangunan dengan jangka waktu 25 tahun dengan menggunakan metode $L C C$. Studi dilakukan pada bangunan kos yang berada di Glagahsari, Yogyakarta.

\section{PROYEK KONSTRUKSI}

Proyek merupakan pekerjaan yang memiliki sifat biaya yang terbatas, durasi pekerjaan yang telah ditentukan, aktifitas pekerjaan yang tidak berulang atau tidak rutin. Berdasarkan konsep dari Life Cycle Cost, terdapat enam tahap dalam melakukan proyek konstruksi, yaitu sebagai berikut (Susilo, 2018):

1. Tahap perencanaan (planning)

Tahap perencanaan merupakan tahap manajemen proyek untuk meletakkan dasar tujuan dan sasaran serta mengatur semua program teknis dan administrasi, sehingga dapat diterapkan. Perancangan merupakan tahapan yang sangat penting dalam proyek konstruksi. Suatu perancangan dikatakan baik ketika semua proses kegiatan dapat diimplementasikan tepat dengan sasaran dan tujuan yang sudah ditentukan.

2. Tahap perancangan (design)

Setelah melakukan perencanaan, tahap berikutnya adalah tahap perancangan yang terdiri dari rancangan kawasan, sarana dan prasarana yang dibutuhkan pada saat pelaksanaan konstruksi. Ada dua tahapan dalam perancangan, yaitu tahap pra desain (preliminary design) dan tahap pengembangan desain (development design) atau desain rinci (detail design).

3. Tahap pengadaan / pelelangan

Tujuan dari tahap pengadaan atau pelelangan adalah untuk memilih kontraktor sebagai pelaksana dan sebagian sub-kontraktor yang melaksanakan konstruksi di lapangan. Beberapa hal yang harus diperhatikan dalam tahapan ini adalah prakualifikasi dan dokumen kontrak.

4. Tahap pelaksanaan (construction)

Tahap pelaksanaan (construction) dilakukan untuk mewujudkan bangunan yang dibutuhkan oleh pemilik proyek dan telah dirancang oleh konsultan perencana dengan biaya dan waktu yang terbatas. Selain itu, mutu atau kualitas dari proyek juga harus terpenuhi. Kegiatan yang ada pada tahap pelaksanaan (construction) adalah membuat rencana, 
mengkoordinasikan, dan memegang kendali semua opersaional di lapangan.

5. Tahap pemeliharaan

Pemeliharaan bertujuan untuk menjamin bangunan yang sudah jadi sesuai dengan dokumen kontrak serta seluruh fasilitas di dalamnya berfungsi atau beroperasi sebagaimana layaknya. Dalam tahap pemeliharaan, kegiatan yang dilakukan adalah sebagai berikut:

a. Mempersiapkan semua data pelaksanaan dan gambar pelaksanaan.

b. Meneliti bangunan secara tepat dan cermat dan melakukan perbaikan jika ada kerusakan.

c. Mempersiapkan tata cara operasional atau pelaksanaan serta mempersiapkan pedoman pemeliharaan.

d. Melatih staf yang akan mengerjakan pemeliharaan.

6. Menganalisis Nilai Akhir

Menganalisis nilai akhir dari suatu aset adalah memperhitungan nilai akhir dari suatu bangunan dengan tujuan untuk memperhitungkan penggantian atau perombakan aset.

\section{BANGUNAN KOST}

Bangunan kost atau sering dikenal sebagai rumah kost adalah jasa yang menawarkan tempat tinggal berupa kamar dengan pembayaran yang biasanya dilakukan tiap bulan. Kost sendiri dalam bahasa Belanda dapat dijabarkan menjadi In de kost, yang berarti "makan di dalam" atau juga bisa diartikan dengan "tinggal dan ikut makan" di dalam rumah yang ditumpangi (Rachmawati, 2017).

Bangunan kost merupakan hunian yang memfasilitasi kamar untuk tinggal, fasilitas yang biasa diberikan merupakan fasilitas standar sebuah kamar. Biaya listrik biasanya diurus oleh pemilik bangunan, tetapi tidak jarang ditemukan biaya listrik pada kost dilimpahkan oleh penghuni kost.

\section{PEMELIHARAAN GEDUNG}

Pemeliharaan gedung adalah kegiatan yang dilakukan untuk menjaga fasilitas pada gedung agar tetap berfungsi selama umur pakai gedung. Tujuan utama dari pemeliharaan gedung adalah sebagai berikut (Kaming dan Yahya, 2019):

1. Untuk penambahan usia gedung.

2. Untuk memastikan keuntungan dari investasi maksimum.

3. Untuk memastikan keamanan pengguna gedung.

4. Untuk memastikan kesiapan operasional pada saat darurat.

Ervianto (2007) dalam Kaming dan Yahya (2019) mengatakan bahwa program pemeliharaan gedung harus dipikirkan secara terstruktur dan berkala untuk seluruh fasilitas yang ada pada gedung. Contohnya dengan mencatat tanggal penggantian suatu elemen bangunan. Berdasarkan hal tersebut, dapat diperkirakan umur dari masing-masing elemen bangunan.

Perencanaan manajemen pemeliharaan gedung didasarkan pada kondisi yang biasanya terjadi pada gedung. Pemilihan program pemeliharaan gedung juga dapat disesuaikan dengan karakteristik dari gedung itu sendiri. Semua kelengkapan elemen pada bangunan dan fasilitas perlu dijaga dengan baik, sehingga saat gedung tersebut digunakan, operasional gedung dapat berjalan dengan semestinya atau berjalan sesuai dengan fungsi gedung tersebut. Masa pemeliharaan dari bagian gedung berbeda satu sama lain, tergantung dari pada siklus hidup bagian gedung tersebut (Kaming dan Yahya, 2019).

\section{KONSEP BIAYA}

Biaya memiliki dua istilah yang penting untuk diperhatikan, yaitu:

1. Biaya (cost) adalah sesuatu yang dikeluarkan untuk memenuhi kebutuhan 
untuk mencapai atau mendapatkan tujuan yang diukur dengan nilai uang.

2. Pengeluaran (expence) merupakan jumlah uang yang digunakan untuk mendapatkan atau mencapai sesuatu yang diharapkan (Susilo, 2018).

Dari biaya tersebut dapat dikelompokkan lagi menjadi dua, yaitu biaya modal (capital cost) dan biaya tahunan (annual cost).

1. Biaya modal (capital cost)

a. Biaya langsung (direct cost) merupakan uang yang dibutuhkan untuk membangun suatu proyek. Biaya ini nantinya akan ditwarkan pada kontraktor, biasanya diberikan oleh pemilik proyek (owner).

b. Biaya tidak langsung (indirect cost) merupakan uang yang dikeluarkan untuk manajemen proyek yang terdiri dari tiga komponen, yaitu biaya yang tidak terduga seperti pajak, overhead (sewa kantor, komputer, dan kontigasi laba). Selain itu, biaya teknik untuk pembuatan desain, biaya perencanaan dan biaya pengawasan selama dilaksankan suatu proyek, gaji pegawai, gaji manajemen dan administrasi. Terakhir adalah bunga (intrest), biaya langsung dan biaya pengawasan selama dilakukannya proses pembangunan diperhitungkan dengan mengikutsertakan bunga.

2. Biaya tahunan (annual cost)

a. Depresiasi adalah penyusutan dari harga atau nilai kamar yang akan disewa.

b. Biaya operasional dan pemeliharaan digunakan untuk memenuhi umur suatau proyek sesuai dengan yang sudah direncanakan.

c. Bunga merupakan biaya perubahan suatu model yang dipengaruhi oleh tingkat suku bunga selama usia proyek.

Giatman (2011) dalam Susilo (2018) mengatakan bahwa istilah -istilah dalam biaya mengalami perkembangan. Sesuai dengan kebutuhan dan tujuan, berikut adalah klasifikasi biaya:

1. Biaya berdasarkan waktunya; adalah biaya masa lalu (hystorical cost), biaya perkiraan (predictive cost) dan biaya aktual (actual cost).

2. Biaya berdasarkan karakter penggunaannya; adalah biaya investasi (investment cost), biaya operasional (operational cost) dan biaya perawatan (maintanance cost).

3. Biaya berdasarkan produknya adalah biaya pabrikasi (factory cost) dan biaya komersial (commercial cost).

4. Biaya berdasarkan volume produk adalah biaya tetap (fixed cost), biaya variabel (variabel cost), biaya semi variabel (semi variabel cost).

\section{LIFE CYCLE COST}

Life Cycle Cost (LCC) merupakan teknik atau metode penting yang digunakan untuk memprediksi dan memperkirakan kinerja biaya dari aset yang dibangun. Selain itu, $L C C$ juga digunakan untuk menentukan apakah satu proyek memenuhi persyaratan kinerja dari klien. Flanagan (1988) dalam Heralova (2017) mengatakan sejarah Life Cycle Cost dimulai pada pertengahan 1960-an di Departemen Pertahanan AS. The Royal Institution of Chartered Surveyors mengenalkan metode pengumpulan data mengenai biaya operasional gedung pada tahun 1971. Untuk membangun proyek Life Cycle Cost, kerangka untuk pengumpulan data diterbitkan pada tahun 1983. Konsep Life Cycle Cost menjadi standar Inggris sejak tahun 1992. Pada tahun 2000 dilakukan revisi terhadap definisi Life Cycle Cost dan dimasukkan dalam ISO 15686 Heralova (2017).

Menurut Floren dkk. (2019), Life Cycle Cost adalah total dana yang digunakan semasa siklus hidup sebuah sistem yang berhubungan langsung dengan biaya kepemilikan selama 
umur ekonomis. Junus dan Fitria (2015) mengatakan definisi Life Cycle Cost adalah metode analisis yang digunakan dalam menghitung nilai ekonomi suatu keputusan pendanaan proyek infrastruktur. Metode $L C C$ berguna untuk membantu menentukan pilihan perancangan dengan menghitung semua biaya semasa umur pakai bangunan yang dinyatakan dalam biaya saat perhitungan itu dilakukan atau present value.

Liano (2019) mengatakan bahwa Life Cycle Cost memperhitungkan aspek biaya, diantaranya adalah biaya awal, biaya oprasional dan pemeliharaan, biaya energi sumber daya, biaya pajak, gaji dan finansial. Jangka waktu pemakaian maksimal dari material yang digunakan mempengaruhi aspek waktu yang ditentukan dari umur hidup gedung. Tingkat bunga juga diperhitungkan dalam penggunaan metode Life Cycle Cost yang dipengaruhi oleh tingkat inflasi.

Berdasarkan Fuller \& Petersen (1996) dalam Junus dan Fitria (2015), Life Cycle Cost merupakan total biaya diskon dari dolar yang berasal dari kepemilikan, pembangunan atau penjualan gedung, operasi, dan pemeliharaan. Selain itu, Life Cycle Cost sebagai suatu metode yang dapat melihat keefektifan biaya sepanjang umur pemakaian desain gedung dan infrastruktur lain (USDA Forest Service, Technology and Development, 2013). Ashworth dan Hogg (2007) dalam Putro dan Raflis (2019) menyebutkan bahwa LCC menilai ulang bermacam-macam bahan dan elemen yang akan dipakai, seperti energi, konsumsi air, dan kinerja keseluruhan aset. Menurut Marliansyah (2015), LCC adalah runtutan kegiatan desain yang berperan untuk mengendalikan biaya awal dan biaya kedepannya untuk investasi. Dalam proses merencanakan Life Cycle Cost, diperlukan pengetahuan tentang service life atau umur pakai dari elemen-elemen bahan bangunan yang akan digunakan. Terdapat beberapa faktor yang penting dalam $L C C$, yaitu umur bangunan (fisik, fungsional, dan ekonomi), umur komponen, suku bunga, perpajakan, metode desain, dan kualitas dalam konstruksi (Kamagi, 2013).

\section{Komponen Life Cycle Cost}

Life Cycle Cost Analysis dirumuskan sebagai berikut:

$$
L C C=C+M+O+R-S
$$

$C$ adalah biaya awal, $M$ adalah biaya perawatan, $O$ merupakan biaya operasional yang terdiri dari biaya energi dan biaya staf, sedangkan $R$ merupakan biaya penggantian dan perubahan fungsi, dan $S$ adalah salvage value.

Komponen yang ada didalam Persamaan 1 tersebut terdiri dari:

1. Biaya

Biaya yang diperhitungkan dalam melakukan analisa Life Cycle Cost adalah biaya awal (initial cost), biaya operasi dan pemeliharaan, biaya penggantian (replacement cost), nilai sisa (residual/salvage value), biaya sumber daya (air, gas, listrik dan bahan bakar), dan biaya lainnya seperti pajak, gaji dan biaya finansial lainnya.

2. Waktu

Periode waktu dapat ditentukan atau dianalisa berdasarkan umur pakai gedung dilihat dari jangka waktu atau umur bahan yang akan digunakan dalam pembangunan gedung. Selain itu, dapat menggunakan periode waktu evaluasi yang dibutuhkan.

\section{Discount rate}

Discount rate adalah tingkat bunga yang memperlihatkan nilai uang investasi terhadap waktu dan dapat menentukan nilai saat ini dari biaya di masa depan.

\section{NET PRESENT VALUE (NPV)}

Net present value merupakan pendekatan yang umum dan sesuai untuk menilai Life Cycle Cost. Cash flow yang didiskonto 
digunakan dalam perhitungan Life Cycle Cost (Heralova, 2014). Cash flow pada proyek yang diperhitungkan adalah keseluruhan biaya modal, operasional, produksi, pemeliharaan, dan pengeluaran (Sugiyarto \& Laksito, 2014).

NPV merupakan jumlah uang bersih dari proyek dan jumlah kenaikan bersih dari pemasukan yang diskonto dari proyek. NPV biasanya digunakan untuk menganalisis kelayakan dari investasi. NPV dikenal juga sebagai metode present value atau nilai sekarang, dengan menghitung Present Worth of the Revenue (PWR) dan Present Worth of the Cost (PWC). Net present value dapat bernilai negatif dan positif (Astuti, et al., 2017). Suatu proyek dikatakan mengalami keuntungan jika nilai dari NPV adalah positif pada tingkat bunganya.

Kriteria dalam menentukan layak atau tidak layaknya pelaksanaan proyek dapat didasarkan pada NPV. Jika NPV positif (>0), maka proyek layak untuk dilaksanakan, sedangkan jika NPV negatif $(<0)$, maka proyek tidak layak untuk dilaksanakan (Astuti, et al., 2017). Berdasarkan metode NPV, analisis finansial diperoleh beberapa kelebihan, yaitu telah memasukkan faktor nilai waktu dari uang, sudah mempertimbangkan seluruh aspek aliran kas proyek (cash flow) dan sudah melakukan perhitungan besaran absolut atau bukan relatif (Sari, et al., 2018).

\section{PENERAPAN LIFE CYCLE COST}

Penelitian analisis Life Cycle Cost pernah dilakukan pada bangunan rumah susun sederhana sewa di Daerah Istimewa Yogyakarta oleh Susilo pada tahun 2018. Penelitian ini menghitung biaya siklus hidup bangunan, mulai dari perencanaan hingga umur ekonomis bangunan. LCC yang terjadi selama 50 tahun sebesar Rp.113.963.999.873, meliputi biaya awal sebesar Rp.67.442.269.546, biaya operasional sebesar Rp.36.136.099.432, biaya perawatan dan penggantian sebesar Rp.9.797.552.532 dan biaya penghancuran sebesar Rp.603.514.329.
Penelitian terkait implementasi metode Life Cycle Cost Analysis pada bangunan ruang kelas di kompleks Gedung Diklat Kabupaten Muara Enim dilakukan oleh Liano (2019). Penelitian ini mengidentifikasi proporsi biaya dan membuat rencana jangka panjang selama 25 tahun terhadap siklus biaya hidup bangunan ruang kelas Gedung Diklat Muara Enim. Hasil penelitian menunjukkan initial cost of construction sebesar Rp.3.695.914.329,91 dengan peresentase 40,65\%. Maintenance cost sebesar Rp.2.586.476.375,88 dengan peresentase $28,40 \%$ dan Operational cost sebesar Rp.2.819.594.574,68 dengan peresentase sebesar 30,96\%.

Kaming, dkk. (2019) melakukan penelitian tentang adopsi Life Cycle Cost untuk Bangunan Gedung Diklat Muara Enim. Serupa dengan penelitian sebelumnya, penelitian ini melakukan estimasi biaya untuk periode 25 tahun dengan presentase yang berbeda, yaitu initial cost of construction dengan presentase 39,12\%. Maintenance and replacement cost dengan presentase $16,28 \%$ dan Operational cost dengan presentase sebesar $44,61 \%$.

Study on life cycle costing: a case of building for private high school in Jakarta dilakukan oleh Kaming dan Yahya (2018). Penelitian tersebut mengidentifikasi praktik pemeliharaan Gedung. Selain itu, tujuan penelitian ini adalah mengidentifikasi umur layanan komponen bangunan dan melakukan rencana biaya siklus hidup dengan periode 25 tahun. Hasil untuk rencana biaya siklus hidup adalah biaya konstruksi sebesar $46 \%$, biaya operasional sebesar 39\% serta penggantian dan pemeliharaan sebesar $15 \%$.

Penelitian yang berjudul analisis rencana Life Cycle Cost Gedung Hostel pada Kawasan Rumah Sakit Jimbun Medika Kediri dilakukan oleh Marliansyah (2015). Tujuan dari penelitian tersebut adalah mengidentifikasi service life komponen material bangunan gedung hostel yang terletak di kawasan 
Rumah Sakit Jimbun Medika Kediri dan membuat rencana jangka waktu panjang dengan life cycle cost. Hasil penelitian tersebut didapatkan rencana jangka panjang life cycle cost didapat besar biaya pembangunan Rp.7.150.000.000,00 dengan persentase $46 \%$, biaya operasional Rp.3.799.333.250,00 dengan persentase 28\%, biaya perawatan dan penggantian Rp.2.590.900.000,00 dengan persentase 26\%.

Penelitian dengan judul analisis Life Cycle Cost pada green building peringkat platinum di Indonesia oleh Putro dan Raflis dilakukan pada tahun 2019. Penelitian tersebut bertujuan untuk mengetahui $L C C$ pada green building dengan tingkat suku bunga $6 \%$ dan periode analisis 17 tahun. Hasil yang didapatkan adalah Rp.1.554.041.286.554. Dengan memasukkan nilai sisa sebesar Rp.282.281.574.483, total Life Cycle Cost menjadi sebesar Rp.1.271.759.712.070.

Studi pengambilan keputusan investasi dengan menggunakan metode Life Cycle Cost Analysis pernah dilakukan oleh Junus dan Fitria (2015). Penelitian ini bertujuan untuk memilih suatu material yang akan dipakai berdasarkan aspek teknis dan biaya yang lebih hemat. Material yang akan menjadi alternatif adalah lampu LED dan lampu T5. Hasil penelitian menunjukkan bahwa penggunaan lampu LED lebih hemat 50\% dibandingkan dengan penggunaan lampu T5. Penelitian ini juga menunjukkan bahwa Life Cycle Cost Analysis dapat digunakan untuk memperkirakan alternatif barang atau sistem yang lebih ekonomis.

\section{METODE PENELITIAN}

\section{Pengumpulan Data dan Analisis}

Proses pengumpulan data diawali dengan perumusan masalah, tujuan dari penelitian, mengumpulkan data yang akan diteliti seperti RAB dari sebuah proyek. Selain itu, dilakukan juga pengumpulan data dari studi literatur yang mendukung penelitian.
Setelah data sudah dikumpulkan, maka penelitian harus menentukan umur pakai dari setiap komponen biaya, serta memperkirakan keadaan pasar di masa yang akan datang, seperti memperkirakan bunga bank, tingkat inflasi dan memperkirakan resiko yang akan terjadi pada saat pembangunan.

Jika semua data yang dibutuhkan telah terkumpul, selanjutnya adalah melakukan analisis data dengan perhitungan Life Cycle Cost menggunakan bantuan MS-Excel.

\section{Objek Penelitian}

Boarding house yang berlokasi di Glagahsari memiliki luas tanah 212,987 $\mathrm{m}^{2}$ dengan jumlah lantai sebanyak tiga lantai dan sembilan kamar. Lantai pertama terdapat kamar yang dibagi menjadi dua tipe, yaitu dua kamar tipe A dengan luas $10 \mathrm{~m}^{2}$ dan dua kamar tipe $B$ dengan luas $11 \mathrm{~m}^{2}$. Selain itu, terdapat fasilitas ruang tamu dengan luas 21 $\mathrm{m}^{2}$, koridor $15 \mathrm{~m}^{2}$, dan lima kamar mandi dengan luas masing-masing 2,5 $\mathrm{m}^{2}$. Pada lantai kedua terdapat dua kamar tipe A dengan luas $10 \mathrm{~m}^{2}$ dan tiga kamar tipe B dengan luas $11 \mathrm{~m}^{2}$. Lantai kedua juga terdapat fasilitas koridor $15 \mathrm{~m}^{2}$, dan lima kamar mandi dengan luas masing-masing $2,5 \mathrm{~m}^{2}$. Untuk lantai ketiga terdapat fasilitas ruang jemur dengan luas $22 \mathrm{~m}^{2}$. Estimasi menggunakan metode Life Cycle Cost Analysis dengan jangka periode waktu 25 tahun.

\section{Model Metode Life Cycle Cost Analysis}

Dalam Kaming dkk. (2019) yang berpedoman pada ISO 15686: 5 for LCC, ada tiga komponen yang melengkapi analisis Life Cycle Cost, yaitu:

1. Initial Development Cost atau Biaya Pembangunan

Biaya yang meliputi semua biaya awal konstruksi termasuk juga biaya yang dibayarkan oleh klien sebagai aset bangunan.

\section{Maintenance Cost}


Semua biaya penggantian, pemeliharaan dan adaptasi aset yang dibangun, salah satunya adalah biaya penggantian material yang tidak terduga, sampai dengan biaya perawatan atau redekorasi bangunan gedung. Untuk mengetahui biaya perawatan, diperlukan umur rencana tiap elemen-elemen dalam pembangunan yang perlu diganti.

\section{Operation Cost}

Biaya yang dikeluarkan untuk operasional gedung dan fasilitas yang ada pada bangunan tersebut. Biaya ini muncul karena adanya kebutuhan yang ditujukan untuk gedung itu sendiri bukan untuk kebutuhan pemilik gedung. Contoh dari biaya operasi adalah biaya gaji staf (cleaning service dan jasa satpam), dan biaya energi.

Gaji staf menurut Sugiyarso (2005) dalam Susilo (2018) adalah jumlah uang yang diberikan kepada pegawai yang bertugas mengurus administrasi dan manajemen yang jumlahnya dibayarkan bulanan. Sedangkan upah adalah imbalan yang diberikan kepada buruh yang melakukan pekerjaan kasar dan lebih banyak mengandalkan fisik, upah biasanya dibayarkan harian.

Biaya energi (listrik) merupakan biaya pokok pengoprasian sebuah gedung. Biaya listrik bergantung pada jumlah dan kapasitas orang yang ada pada sebuah bangunan.

\section{HASIL dan PEMBAHASAN}

\section{Analisis Data}

Untuk mengetahui umur pakai dari komponen yang akan digunakan pada bangunan tersebut maka dapat dilihat dari data acuan literatur penelitian yang serupa dan dari klaim produk produsen. Berikut adalah daftar umur pakai yang dapat dilihat pada Tabel 1 .

\section{Perhitungan Life Cycle Cost}

Initial cost yang diperoleh dari PT. Rahayu Trade \& Contractor adalah Rp.1.261.887.140, 93. Detail dari nilai biaya pada setiap pekerjaan dapat dilihat pada Tabel 2.

Dari Tabel 2. biaya pembangunan yang memiliki persentase terbesar adalah pekerjaan struktur, yaitu sebesar 30,25\% dengan biaya Rp.383.601.612,19. Nilai persentase terbesar kedua adalah pekerjaan pasangan dan plesteran sebesar 27,83 \% dengan biaya Rp.352.856.110,23 dan ketiga adalah pekerjaan mekanikal yang memiliki persentase sebesar 11,09 \% dengan biaya Rp.140.666.569,90.

Pada Tabel 2 juga dapat dilihat tiga persentase yang paling kecil adalah pekerjaan plafond yang memiliki nilai persentase $1,86 \%$ dengan biaya Rp.23.568.462,00, lalu ada pekerjaan lain dengan persentase 1,93\% dengan biaya Rp.24.510.000,00 dan pekerjaan tanah dan pasir dengan persentase $2,98 \%$.

Tabel 1. Daftar umur layan komponen bangunan

\begin{tabular}{clc}
\hline Kelompok & Komponen Bangunan & $\begin{array}{c}\text { Umur } \\
\text { Pakai } \\
\text { (tahun) }\end{array}$ \\
\hline Atap & Streel Roof Frame & 30 \\
& Roof Clay Tile & 20 \\
& Gutter & 15 \\
Dinding & Wall Paint & 8 \\
& Aluminium Paint & 12 \\
& Wood Paint & 15 \\
& Frame Aluminium & 15 \\
& Door Aluminium & 15 \\
& Timber Frame & 30 \\
& Timber Door & 30 \\
& Timber Window & 30 \\
& Door and Window & 20 \\
& Glass & 20 \\
Lantai & Granit & 20 \\
& Ceramic & 15 \\
Plafon & Gypsum & 18 \\
& GRC & 8 \\
& Wastafel & 12 \\
& Stainless Steel Sink & 3 \\
& Water Crane & 15 \\
& Water Closet & 8
\end{tabular}




\begin{tabular}{clc} 
& Floor Drain & 8 \\
Asesori & PVC pipe & 30 \\
& Slot Door \& Window & 10 \\
& HandleDoor\& Window & 10 \\
ME & Hinge Door \& Window & 20 \\
& Lamp Standart & 5 \\
& Lamp Down Light & 5 \\
& Wall Stop Contact & 20 \\
Saclar Single & 20 \\
& Saclar Multiple & 20 \\
& Fitting & 20 \\
Lif & 30 \\
Fire Alaram & 30 \\
Telephon & 15 \\
CCTV & 30 \\
Water Heater & 15 \\
AC & 15 \\
\hline
\end{tabular}

(Sumber: Kaming, et al., 2019)

Tabel 2. Biaya pembangunan

\begin{tabular}{|c|c|c|c|}
\hline No & $\begin{array}{c}\text { Jenis } \\
\text { Pekerjaan }\end{array}$ & Persentase & Biaya \\
\hline 1 & $\begin{array}{l}\text { Pekerjaan } \\
\text { Persiapan }\end{array}$ & $3,65 \%$ & Rp.46.239.200,00 \\
\hline 2 & $\begin{array}{l}\text { Pekerjaan } \\
\text { Tanah dan } \\
\text { Pasir }\end{array}$ & $2,98 \%$ & Rp.37.751.604,97 \\
\hline 3 & $\begin{array}{l}\text { Pekerjaan } \\
\text { Struktur }\end{array}$ & $30,25 \%$ & $\begin{array}{l}\text { Rp.383.601.612,1 } \\
9\end{array}$ \\
\hline 4 & $\begin{array}{l}\text { Pekerjaan } \\
\text { Pasangan } \\
\text { dan } \\
\text { Plesteran }\end{array}$ & $27,83 \%$ & $\begin{array}{l}\text { Rp.352.856.110,2 } \\
3\end{array}$ \\
\hline 5 & $\begin{array}{l}\text { Pekerjaan } \\
\text { Pasangan }\end{array}$ & $5,72 \%$ & Rp.72.508.303,21 \\
\hline 6 & $\begin{array}{l}\text { Pekerjaan } \\
\text { Plafond }\end{array}$ & $1,86 \%$ & Rp.23.568.462,00 \\
\hline 7 & $\begin{array}{l}\text { Pekerjaan } \\
\text { Pintu dan } \\
\text { Jendela }\end{array}$ & $5,07 \%$ & Rp.64.334.000,00 \\
\hline 8 & $\begin{array}{l}\text { Pekerjaan } \\
\text { Pengecatan }\end{array}$ & $4,88 \%$ & Rp.61.853.028,43 \\
\hline 9 & $\begin{array}{l}\text { Pekerjaan } \\
\text { Mekanikal }\end{array}$ & $11,09 \%$ & $\begin{array}{l}\text { Rp.140.666.569,9 } \\
0\end{array}$ \\
\hline 10 & $\begin{array}{l}\text { Pekerjaan } \\
\text { Elektrikal }\end{array}$ & $4,26 \%$ & Rp.53.998.250,00 \\
\hline \multirow[t]{2}{*}{11} & $\begin{array}{l}\text { Pekerjaan } \\
\text { Lain-Lain }\end{array}$ & $1,93 \%$ & Rp.24.510.000,00 \\
\hline & Jumlah & $100,00 \%$ & $\begin{array}{l}\text { Rp.1.261.887.14 } \\
\text { 0,0 }\end{array}$ \\
\hline
\end{tabular}

Maintanance cost dihitung dengan jangka waktu 25 tahun terhitung dari tahun 2019 hingga 2044. Perhitungan Life Cycle Cost setiap pekerjaan penggantian dan pemeliharaan dapat dilihat pada Tabel 3. Hasil analisis yang diperoleh dengan mempertimbangkan nilai inflasi $6 \%$ dan dengan nilai NPV Rp.427.879.959.

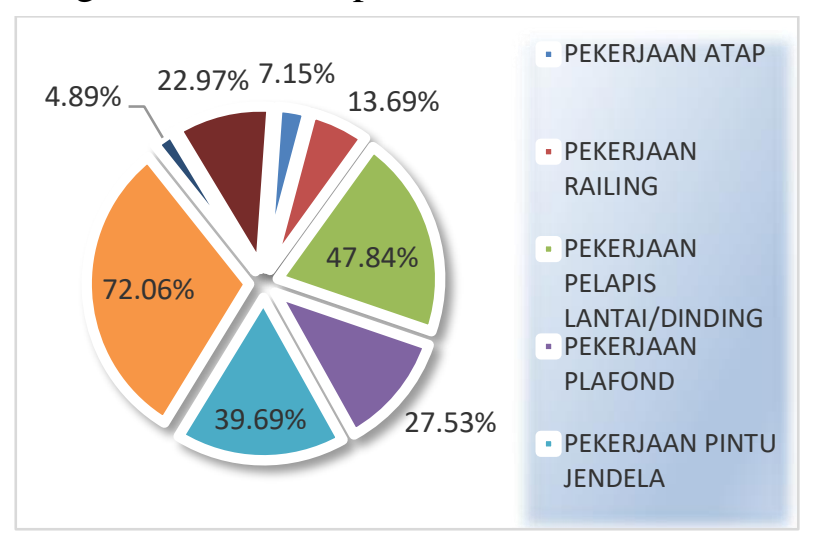

Gambar 1. Proporsi biaya penggantian dan pemeliharaan

Tabel 3. Biaya maintenance

\begin{tabular}{cll}
\hline $\begin{array}{c}\text { Present } \\
\text { Value }\end{array}$ & Biaya Tahunan & \multicolumn{1}{c}{ NPV } \\
\hline Tahun ke-3 & Rp.5.067.705 & Rp.4.254.845 \\
Tahun ke-5 & Rp.20.605.200 & Rp.15.398.266 \\
Tahun ke-6 & Rp.5.540.010 & Rp.3.905.707 \\
Tahun ke-7 & Rp.0 & Rp.0 \\
Tahun ke-8 & Rp.12.831.700 & Rp.8.050.609 \\
Tahun ke-9 & Rp.7.186.695 & Rp.4.253.805 \\
Tahun ke-10 & Rp.181.585.675 & Rp.101.397.441 \\
Tahun ke-12 & Rp.8.599.355 & Rp.4.273.879 \\
Tahun ke-14 & Rp.0 & Rp.0 \\
Tahun ke-15 & Rp.290.903.093 & Rp.121.393.861 \\
Tahun ke-16 & Rp.20.447.000 & Rp.8.047.939 \\
Tahun ke-18 & Rp.12.143.770 & Rp.4.253.963 \\
Tahun ke-20 & Rp.339.775.432 & Rp.105.941.980 \\
Tahun ke-21 & Rp.14.467.000 & Rp.4.256.191 \\
Tahun ke-24 & Rp.54.252.745 & Rp.13.400.428 \\
Tahun ke-25 & Rp.124.682.600 & Rp.29.051.046 \\
& Total & Rp.427.879.959 \\
\hline
\end{tabular}

Dilihat dari Gambar 1, biaya perawatan dan penggantian pekerjaan pengecatan merupakan biaya yang paling besar yaitu sebesar $72,06 \%$, yang kedua adala biaya pekerjaan pelapis lantai / dinding yaitu sebesar $47,84 \%$, dan terbesar ketiga adalah biaya 
pekerjaan pintu jendela yang memiliki persentase $39,69 \%$. Biaya operasional gedung juga menggunakan nilai inflansi $6 \%$ mencapai nlai sebesar Rp.605.914.200. Komponen dari biaya operasional pada gedung ini terdiri dari penjaga kos, cleaning service, dan utilitas biaya energi yang terdiri dari listrik, telepon dan internet. Detail dari perhitungan operasional dapat dilihat pada Tabel 4.

Tabel 4. Operational cost

\begin{tabular}{|c|c|c|c|c|}
\hline No & Kelompol & Jumlah & $\begin{array}{l}\text { Harga } \\
\text { Satuan }\end{array}$ & $\begin{array}{c}\text { Jumlah } \\
\text { Harga }\end{array}$ \\
\hline \multirow[t]{2}{*}{1} & Penjaga & 1 & Rp.1.500.0 & Rp.1.500.00 \\
\hline & Kost & & $00,-$ & $0,-$ \\
\hline \multirow[t]{2}{*}{2} & Cleaning & 1 & Rp.1.750.0 & Rp.1.750.00 \\
\hline & Service & & $00,-$ & $0,-$ \\
\hline \multirow[t]{10}{*}{3} & Utilitas & & & \\
\hline & Biaya & & & \\
\hline & Energi & & & \\
\hline & -Listrik & 1 & $\begin{array}{l}\text { Rp.200.000 } \\
\text {,- }\end{array}$ & $\begin{array}{l}\text { Rp.200.000, } \\
\text { - }\end{array}$ \\
\hline & Telp dan & 1 & Rp.500.000 & Rp.500.000, \\
\hline & & Tot & ,- & $\overline{\mathrm{Rp}} .3 .950 .00$ \\
\hline & & & & \\
\hline & & Total & per tahun & Rp.47.400.0 \\
\hline & & $\mathrm{P} / \mathrm{A}$ & $\mathrm{i}=6 \%$ & $\begin{array}{l}00,- \\
12,783\end{array}$ \\
\hline & & Total $l i$ & fe cycle cos & $\begin{array}{l}\text { Rp.605.914 } \\
.200,\end{array}$ \\
\hline
\end{tabular}

Setelah menghitung nilai initial cost, maintanance cost dan operational cost didapatkan jumlah biaya keseluruhan sebesar Rp.2.295.681.300,00. Total perhitungan $L C C$ 25 tahun dapat dilihat pada Tabel 5. Dengan nilai persentasi untuk initial cost sebesar $54,97 \%$ dengan jumlah harga Rp.1.261.887.141,00, maintanance cost sebesar 18,64\% dengan jumlah harga Rp.427.879.959,00, dan operational cost sebesar 26,39\% dengan jumlah harga Rp.605.914.200,00. Persentase dari total life cycle cost terdapat pada Gambar 2.

Tabel 5. Total biaya $L C C$

\begin{tabular}{clc}
\hline No & \multicolumn{1}{c}{ Uraian } & Jumlah Harga \\
\hline 1 & Biaya & Rp.1.261.887.141, 00 \\
& $\begin{array}{l}\text { Pembangunan } \\
\text { (Initial cost) }\end{array}$ & \\
& &
\end{tabular}
2 Biaya
Rp.427.879.959, 00
Penggantian
dan
pemeliharaan
(Maintenance
cost)
3 Operational Rp.605.914.200,00 cost

Total Rp.2.138.747.606, 00

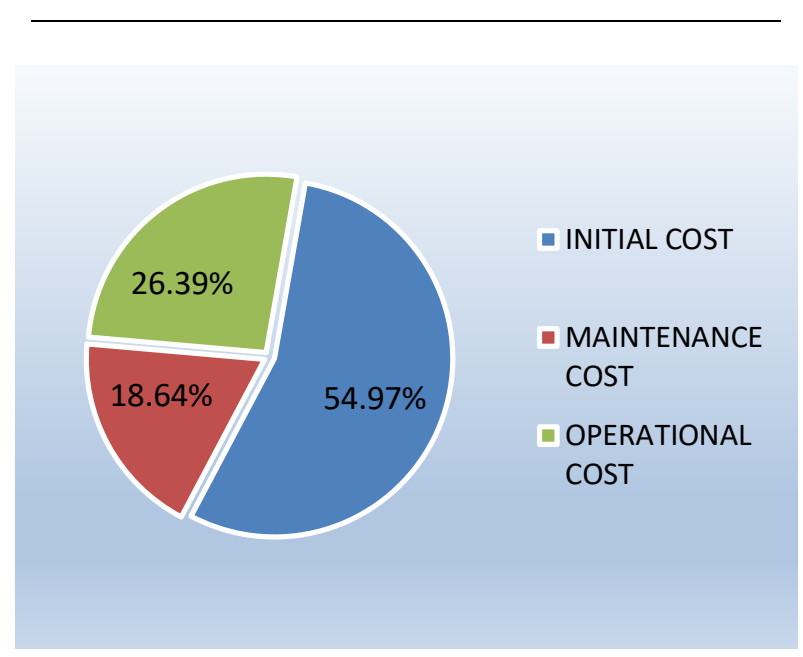

Gambar 2. Proporsi biaya total bangunan

\section{KESIMPULAN}

Life cycle cost merupakan alat untuk mengontrol biaya dengan estimasi dasar dari awal perencanaan gedung dan pemeliharaan pasca pembangunan. Life Cycle Cost menghitung semua aspek biaya yang akan dikeluarkan sepanjang siklus hidup suatu bangunan, termasuk tingkat suku bunga juga diperhitungkan dalam Life Cycle Cost.

Estimasi biaya keseluruhan gedung dengan metode Life Cycle Cost yang dilakukan pada bangunan kos yang berlokasi di Glagahsari dibagi menjadi tiga kelompok estimasi biaya, yaitu initial cost sebesar Rp.1.261.887.141 dengan persentase 54,97\%, maintanance cost sebesar Rp.427.879.959 dengan persentase $18,64 \%$, dan operational cost sebesar Rp.605.914.200 dengan persentase $26,39 \%$. 


\section{REFERENSI}

A, H. A., Sugiyarto, \& Laksito, B. (2014). Analisis Investasi Bangunan Gedung (Studi Kasus Pada Proyek Pembangunan Gedung Rawat Inap RSUP Dr.Kariadi Semarang. Matriks Teknik Sipil: 297-304.

Floren, Kaming, P. F., \& Ervianto, W. I. (2019). Model Pemeliharaan Infrastruktur Embung Berbasis Biaya Siklus Hidup Di Kabupaten Sleman DIY. Jurnal Manajemen Aset Infrastruktur \& Fasilitas. 3: 13-22.

Heralova, R. S. (2017). Life Cycle Costing as an Important Contribution to Feasibility Study in Construction Projects. Procedia Engineering. 196: 565-570.

Heralova, S. R. (2014). Life Cycle Cost Optimization Within Decision Making on Alternative Designs of Public buildings. Procedia Engineering. 85: 454-463.

Junus, T. D., \& Fitria, D. (2015). Pengambilan Keputusan Investasi dengan Menggunakan Metode Life Cycle Cost Analysis. Green Building Engineers, Divisi Sustainability, PT Asdi Swasatya.

Kamagi, G. P. (2013). Analisis Life Cycle Cost pada Pembangunan Gedung (Studi Kasus: Proyek Bangunan Rukun Bahu Mall Manado). Jurnal Sipil Statik. 1(8): 549-556.

Kaming, P. F., \& Yahya, O. A. (2019). Study on Life Cycle Costing : A Case of Building for Private High School in Jakarta. MATEC Web of Conferences 258. EDP Sciences, 1-8.

Kaming, P. F., Liano, I. H., \& Sigit, W. A. (2019). Adopsi Life Cycle Costing untuk Bangunan Gedung Diklat Muara Enim. Jurnal Rekayasa Konstruksi Mekanika Sipil. 2(2): 121-131.
Liano, I. H. (2019). Implementasi Metode Life Cycle Cost Analysis pada Bangunan Ruang Kelas di Kompleks Gedung Diklat Kabupaten Muara Enim. Civil Enginering and Environmental Symposium.

Marliansyah, J. (2015). Analisis Rencana Life Cycle Cost Gedung Hostel pada Kawasan Rumah Sakit Jimbun Medika Kediri. Yogyakarta: Universitas Atma Jaya Yogyakarta.

Putro, R. W., \& Raflis. (2019). Analisis Life Cycle Cost pada Green Building Peringkat Platinum Di Indonesia. Prosiding Seminar Intelektual Muda. Jakarta: ISBN :978-623-91368-0-2, 368373.

Rachmawati, A. (2017). Membangun Informasi Layanan Umum Rumah Kos Melalui Aplikasi Berbasis Web. Jurnal Ilmiah FIFO, 155-162.

Sari, C. F., Sawaki , M. E., \& Sabarofek, M. S. (2018). Pengaruh Analisis Investasi Terhadap Kelayakan Penambanganb Batu Mangan Di PT. Berkat Esa Mining. Journal Universitas Sarjanawiyata Tamansiswa. 4(1): 11-18.

Susilo, E. (2018). Analisis Life Cycle Cost pada Bangunan Rumah Susun Sederhana Sewa Di Daerah Istimewa Yogyakarta. Yogyakarta: Universitas Islam Indonesia Yogyakarta.

Astuti, M., Sri F. \& Sugiyanto. (2017). Studi Kelayakan Investasi Proyek Pembangunan Tower 5 Karawaci Tangerang Selatan. Matriks Teknik Sipil. 981-989. 